\title{
Informative value of the use of infrared thermography in the complex diagnosis of postpartum dysgalactia syndrome in sows
}

\author{
Evgeniya Sergeevna Latynina*, Georgy Petrovich Dyulger, Leonid Borisovich Leontiev \\ Russian Timiryazev State Agrarian University, 127550 Moscow, Russia
}

\begin{abstract}
The article presents scientific materials on the use of the method of remote infrared thermography in the complex diagnosis of postpartum dysgalactia syndrome in sows. The general body temperature and the temperature of the skin surface of individual parts of its body are important indicators of the functional state of the animal body. In veterinary practice, they are widely used for the diagnosis and differential diagnosis of various diseases. Now, the most perfect way to register the spatial distribution of temperatures is the method of infrared thermography. Infrared thermography is the process of obtaining a visible image of an object based on its infrared radiation, which is low-energy and invisible to the human eye. Infrared radiation from the skin depends on both external and internal factors. Their change will undoubtedly affect the thermal conductivity of the body and reflect itself on thermograms in the form of thermal patterns of various color grading. Despite the abundance of factors affecting skin radiation, infrared thermography is a promising method for the timely diagnosis of many diseases. The undoubted advantages of this method are its non-invasiveness, the absence of contraindications and species-specificity, and the non-invasiveness of the examination. In this connection, the purpose of this study was to determine the information content of the use of infrared thermography in the complex diagnosis of postpartum dysgalactia syndrome in sows.
\end{abstract}

\section{Introduction}

Pigs have a high reproductive and productive potential. They are distinguished by high early maturity, fertility, with a relatively short duration of pregnancy (114-116 days) and lactation (21-28 days), they can effectively mate almost immediately after weaning of piglets and have up to $2.6-2.8$ or more farrowings per year.

The syndrome of postpartum dysgalactia is one of the most difficult problems in the pig industry and the reason for the high mortality of suckling pigs in the early stages of lactation. In various foreign and especially domestic sources, this symptom complex is also described as metritis-mastitis-agalactia syndrome, postpartum septicemia, prenatal hypogalactia, agalactic toxemia, postpartum milk fever, etc. [1 - 6].

The clinical manifestations of the symptom complex are diverse. Its main (leading) manifestation is hypogalactia - a pronounced decrease in milk production in the first $12 \ldots 48$ hours after farrowing and, therefore, underfeeding and hunger of newborn piglets, leading to a delay in their growth and death [7].

The term postpartum hypogalactia syndrome was proposed in 1992 by G.-P. Martineau et al., and in 1998 it was renamed the postpartum dysgalactia syndrome
(PDS), which is now well known and accepted by the world scientific community [8].

The terms postpartum dysgalactia syndrome and metritis-mastitis-agalactia" are not completely equivalent. Currently, the use of the term metritis-mastitis-agalactia is often considered incorrect due to the variability of the observed clinical symptoms [9]. In the context of the metritis-mastitisagalactia syndrome, the termagalactia can be misleading, since in most cases it does not mean a complete cessation of milk production, but only generalizes the dysgalactic disorders encountered [10]. Total and uncomplicated agalactia practically does not occur $[11,12]$.

In some cases, mastitis may be the only diagnosed symptom, which later more often causes hypogalactia than agalactia $[11,13]$. According to modern concepts, MMA syndrome is considered a severe form of postpartum dysgalactia syndrome [12]. Pathomorphological research methods have also established that in sows it is mainly not metritis that is recorded (inflammation covers all the membranes of the uterus), but endometritis, in which inflammation of the organ does not extend beyond the endometrium [14].

It should also be noted that insufficient lactation can also be caused by malformations of the mammary

\footnotetext{
* Corresponding author: evgenialatynina@ $\mathrm{rgau}-\mathrm{msh}$.ru
} 
glands, dyshormonal disorders, as well as the inability of the body to adapt to lactation [15].

Decreased lactation is the leading problem of this syndrome [12]. Also, colostrum composition changes in sows with this syndrome, which is characterized by a higher concentration of lactose and a lower concentration of proteins, fats, and sodium [16].

Thus, the postpartum dysgalactia syndrome (PDS) is a group of diseases characterized by deterioration in the health of the sow, accompanied by a decrease in milk production and increased mortality of newborn piglets in the first 12-48 hours after farrowing [16-18].

The syndrome of postpartum dysgalactia causes significant economic damage to production - postnatal reproductive losses increase due to an increase in early mortality of piglets, the costs of treating and caring for sick sows increase, the fertility of animals in the next reproductive cycle decreases and the number of dry runs increases, etc. [19]. In this regard, now, one of the topical issues is the development and implementation of timely informative diagnostic measures.

The purpose of this work is to determine the informative value of the use of infrared thermography in the complex diagnosis of postpartum dysgalactia syndrome in sows.

\section{Materials and research methods}

The studies were carried out in LLC SEC Mashkino and at the Department of Veterinary Medicine of the Federal State Budgetary Educational Institution of Higher Education of the Russian State Agrarian University Moscow Agricultural Academy named after K.A. Timiryazev.

LLC Cattle industrial complex Mashkino is in the village. Industry, Kolomensky district, Moscow region. The main activity of the company is the breeding of large white, landrace, and maxter pigs, as well as their crossbreeds. According to its purpose, the farm is a commercial one, with a complete production cycle (1920 thousand heads per year).

The studies were carried out in June - August 2019 and 2020. on 185 deep-feeding and farrowing sows of various ages and parity.

The experimental animals were kept in special farrowing pens. The sows were transferred to the birthing section 7-10 days before the expected farrowing. Farmed queens were kept together with newborn piglets until weaning at the age of 22 days.

The conditions for keeping and feeding the experimental animals were the same. The animals were fed according to the VIZ standards, considering their physiological state. Prophylactic zooveterinary measures were carried out strictly according to the schedule developed at the enterprise and agreed with the SBBZH of the district.

Diagnosis of the disease was carried out according to anamnesis, a comprehensive clinical and instrumental study of sows (1-2 days before farrowing and during the first 3 days after it), the results of dynamic observation of the sucking activity of newborn piglets, as well as by assessing the functional activity of the mammary glands using oxytocin test.

The diagnostic criteria for the development of the syndrome of postpartum dysgalactia were hyperthermia (rectal body temperature $\geq 39.5^{\circ} \mathrm{C} 1-2$ days before the survey and in the first 12-48 hours after farrowing), purulent or catarrhal-purulent discharge from the genital loop after farrowing, mastitis and/or a negative oxytocin test: when the milk flow reflex is stimulated by oxytocin (15 minutes after weaning the pigs), milk is not released or is released dropwise.

To assess the informativeness of the use of infrared thermometry in the complex diagnosis of postpartum dysgalactia syndrome, 40 animals were selected. According to the principle of analogs, the experimental sows were divided into experimental (with symptoms of postpartum dysgalactia syndrome; $\mathrm{n}=20$ ) and control (healthy animals; $\mathrm{n}=20$ ) groups. Thermography of mammary glands and suckling pigs was carried out using a TVS300-med thermal imager (OOO STK SILAR, St. Petersburg).

The advantage of this thermal imager is its portability, uncooled microbolometer array, high spatial resolution and frame rate, and high-temperature resolution - up to $0.03^{\circ} \mathrm{C}$. The research results were recorded using a personal computer with a special program for analyzing the obtained thermograms Radiometric Thermography Studio Complete. The thermal imager software made it possible to select and fix the image in areas with temperatures exceeding the value set by the user. The apparatus was mounted on a tripod at 1 meter from the animal. The duration of the study of one zone (excluding adaptation time) is 3-5 minutes.

The study was carried out under standardized conditions, namely, at a temperature of 20-24 ${ }^{\circ} \mathrm{C}$ (thermal comfort zone) without air blowing, with the exclusion of exposure to sources of both heat and cold; after adaptation with open skin in the examination area for at least 15 minutes. The foci of the pathological process in the mammary gland due to a local increase/decrease in temperature were reflected on the thermograms in the form of thermograms of various color grading (from the hottest - white to the coldest violet). The informative value of the method was determined by the indicators of sensitivity and specificity, calculated by the formulas:

Sensitivity calculation:

Sens=TP: $(\mathrm{TP}+\mathrm{FN}) \times 100 \%$,

where Sens is the sensitivity, TP is the number of sows with a truly positive result, $\mathrm{FN}$ is the number of sows with a false negative result.

\section{Specificity calculation: \\ Spec $=\mathrm{TN}:(\mathrm{TN}+\mathrm{FP}) \times 100 \%$,}

where Spec is specificity, TN is the number of sows with a truly negative result, FP is the number of false positive sows.

Along with the method of infrared thermography, ultrasound examination of the mammary gland and internal genital organs (uterine horns) of sows was carried out. The study of milk bags was carried out in Bmode, using a convex probe with a frequency of $5 \mathrm{MHz}$, 
on a digital portable ultrasound device AcuVista VT880b (LLC Ray Systems, Russia). During ultrasound scanning of the mammary gland, the sows were in a standing position.

The contact method of obtaining an image using an acoustic gel was used. Milk bags were examined alternately from the ventral, lateral, and medial sides (at different angles, from different points, and in different planes). The examination of the internal genital organs of sows was also carried out on an AcuVista VT880b ultrasound apparatus according to the following technique - an acoustic gel was applied to the working surface of a convex transducer with a frequency of 3.5 $\mathrm{MHz}$ and applied to the ventral hairless abdomen in the region of the last three pairs of milk bags. First, the urinary bladder was visualized, then moving the scan area forward, the uterine horns were visualized according to the characteristic echo structure. The most informative images were recorded and archived for their subsequent detailed study.

To confirm mastitis in sows, a laboratory study of the number of somatic cells in the secretion of the mammary gland was carried out on a DeLaval analyzer, as well as the cytological method was used to determine what these cells are in milk - leukocytes, epithelium, erythrocytes, or all in total. The reference indicators were taken from the "Guidelines for the diagnosis of therapy and prevention of diseases of the reproductive organs and mammary gland in pigs" [20].

Before milk collection, the milk bags were washed and dried, the nipples were disinfected with a $70 \%$ alcohol solution and dried with a disposable sterile napkin. then oxytocin was administered at a dose of 30 IU / m. During cleaning and disinfection of the mammary gland, newborn piglets were fenced off from the sow, and a few minutes after the application of oxytocin, the mammary gland was stimulated, and milk was taken. Milk was taken as a cumulative sample from at least three milk bags, with the first stream of milk being milked into a separate container and subsequently disposed of, and the subsequent ones were milked directly into a sterile plastic cup, which was appropriately labeled. The method of carrying out the oxytocin test is based on the "Guidelines for the

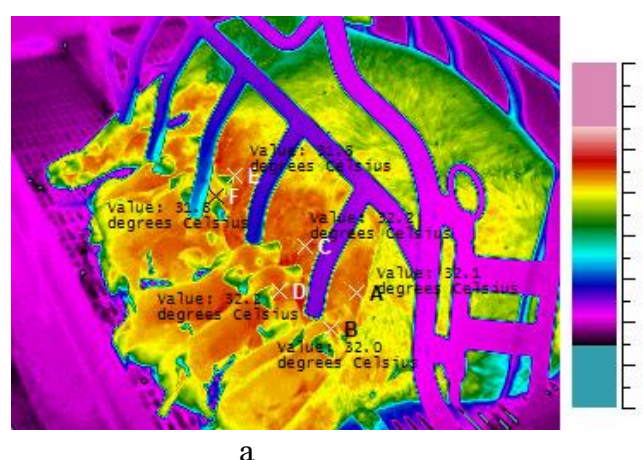

diagnosis, therapy, and prevention of diseases of the reproductive organs and mammary gland in pigs" [20].

The resulting digital material was processed statistically. The assessment of the reliability of differences for $\mathrm{P}<0.05$ was carried out using the Student's t-criteria for absolute paired values.

\section{Results and Discussions}

As a result of the clinical examination, the number of healthy sows was 135 heads $(73.1 \%)$, and individuals with symptoms of postpartum dysgalactia syndrome were identified 50 heads, respectively (26.9\%).

According to the data obtained as a result of instrumental studies, a symmetrical uniform temperature distribution was observed on the thermograms of the control group throughout the mammary gland, as well as among suckling pigs (Fig. 1a). The average value of the surface temperature of the mammary gland of sows was $31.3 \pm 0.7^{\circ} \mathrm{C}$ on the first day after farrowing, on the second day - 31.9 $\pm 0.6{ }^{\circ} \mathrm{C}$, and on the third day $-32.0 \pm$ $0.5{ }^{\circ} \mathrm{C}(\mathrm{p}<0,05)$.

In the sows of the experimental group, the thermograms were different (Fig. 1b). Thermal patterns of the lobes of the mammary gland and adjacent suckling pigs differed greatly in color. In 8 sows with partial agalactia, thermopatterns had a yellow-green color and an average skin surface temperature on the first day after farrowing $28.3 \pm 0.8^{\circ} \mathrm{C}$, on the second $-29.5 \pm 0.5^{\circ} \mathrm{C}$ and on the third day $-28.8 \pm 0,9^{\circ} \mathrm{C}(\mathrm{p}<0.05)$. Edema of the mammary gland in sows $(n=12)$ was expressed as a white-colored thermo-pattern (the temperature of the skin surface was increased, its average value in the group on the first day of lactation was $33.8 \pm 0.5^{\circ} \mathrm{C}$, on the second - 34.1 $\pm 0,6{ }^{\circ} \mathrm{C}$ and in the third $-34.9 \pm 0.7^{\circ} \mathrm{C}$ $(p<0.05))$. As a result of the analysis of the data obtained, the sensitivity $(\mathrm{H})$ of the method for diagnosing breast pathologies in sows by the method of infrared thermography was $94,4 \%$, the specificity (C) was $89,5 \%(\mathrm{H}=17:(17+1) \times 100=94.4 \% ; \mathrm{C}=17:(17$ +2) $\mathrm{x} 100=89.5 \%$ ).

All animals with mammary gland edema were diagnosed with subclinical mastitis according to laboratory milk tests.

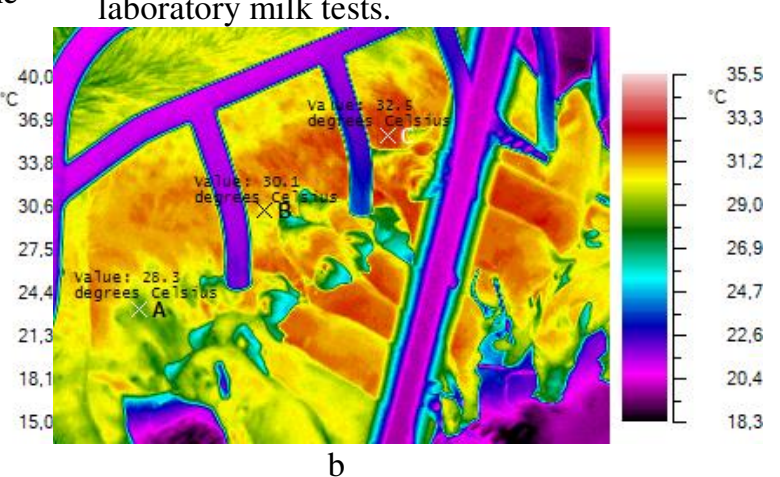

Fig. 1. Thermograms of the control (a) and experimental groups (b)

The data of laboratory analyzes of the secretion of the mammary gland showed an excess of the content of leukocytes (eosinophils, basophils, and neutrophils) in the milk of sows. The value in the experimental group on the first day of the examination was $(4.6 \pm 1.9) \times 106$ units per $\mathrm{ml}(\mathrm{p}<0.05)$, in the second $-(5.07 \pm 1.6) \times 106$ $(\mathrm{p}<0,05)$, and on the third day of the examination - (5.6 
$\pm 2.4) \times 106$ units per $\mathrm{ml}(\mathrm{p}<0.05)$ with a normal value of up to 2.0 million / $\mathrm{ml} \mathrm{[20].}$

During an ultrasound examination, the following echographic signs of endometritis were observed in sows with vaginal discharge - an increase in the thickness of the uterine wall and the accumulation of anechoic contents in the uterine horns (Fig.2b). On the echograms of healthy sows, there are no anechoic structures, the uterine horns are practically not visualized (Fig. 2a).

Ultrasonograms of the parenchyma of a physiologically healthy mammary gland showed

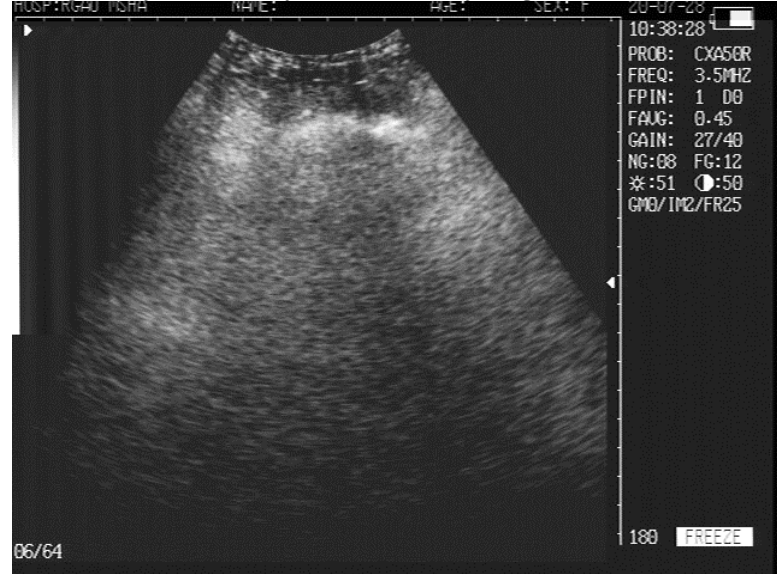

a homogeneous echogenicity and isolated anechoic milk ducts and vessels (Fig. 3a). In sows with observed signs of impaired lactation (hypogalactia, mastitis, agalactia), echograms show various pathological changes in the form of hyperechoic formations of various diameters, cavities filled with hypo- or anechoic fluid, a decrease in the volume of the parenchyma of the mammary gland (with hypogalactia) both in the sagittal and in the axial plane (Fig. 3b).

Fig. 2. Echograms of the uterine horns of sows in norm (a) and with endometritis (b)

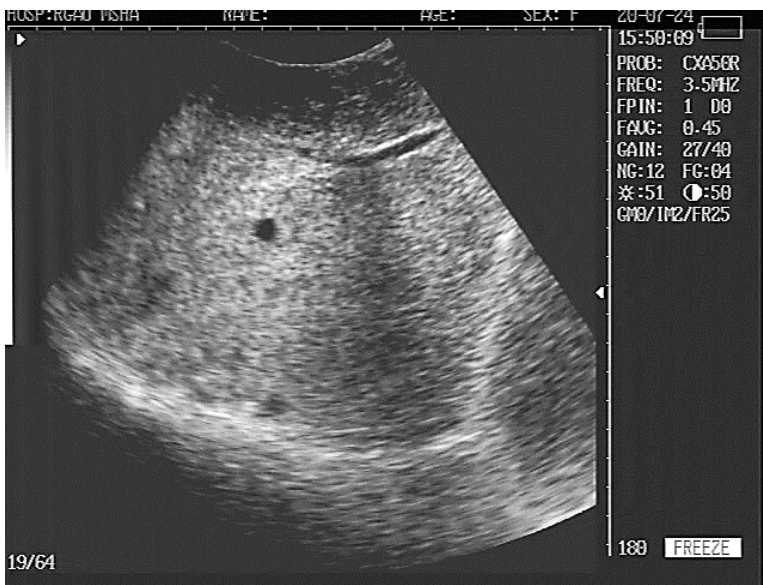

a

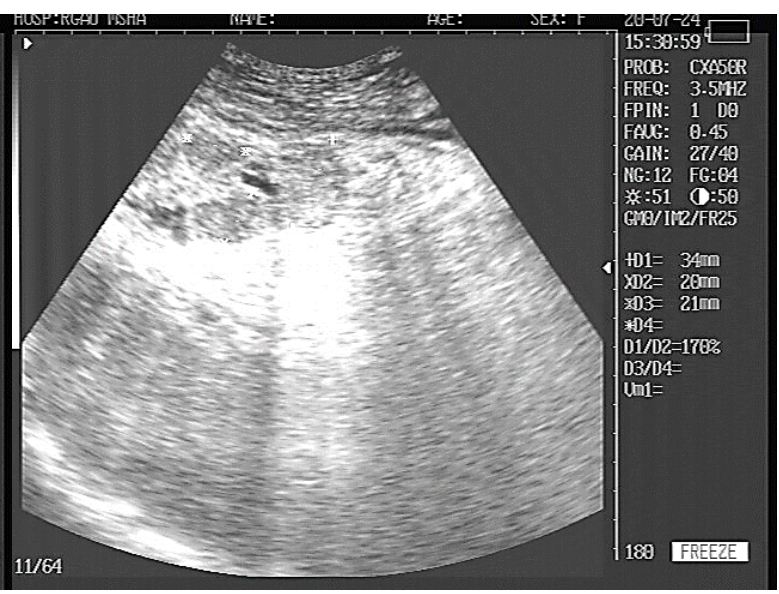

b

Fig. 3. Echograms of the mammary gland of sows in norm (a) and with pathology (b)

\section{Conclusion}

The results obtained during the research allow us to conclude that remote infrared thermography is an informative research method that allows in real-time to assess the morphological and functional state of the mammary glands of lactating sows and the usefulness of the sucking activity of suckling pigs. When assessing the morphological and functional state of milk bags, the sensitivity of the method is $94.4 \%$, and the specificity is $89.5 \%$.

\section{References}

1. V.N. Kotsarev, N.I. Shumsky, A.G. Nezhdanov, V.Y. Boev, On the issue of etiology, diagnosis, prevention and therapy of postpartum purulentinflammatory diseases of the genital organs in sows, Bulletin of the Voronezh SAU, 4(39), 225-229 (2013)

2. V.V. Serebryakov, Microbiocenosis of reproductive organs and mammary glands of sows with metritismastitis-agalactia syndrome, candidate dissertation, 128 p. (Omsk, 2009)

3. L.M. Ushakova, The effectiveness of using the drug Metramag-15® for the prevention and treatment of postpartum endometritis and metritis-mastitis- 
agalactia syndrome in sows, candidate dissertation (Saratov, 2020) 162 p.

4. V.P. Khlopitsky, Symptomatic infertility of broodstock of pigs at industrial enterprises, and pharmacological correction of their reproductive function, dissertation (Voronezh, 2014) 357 p.

5. H. Bostedt, G. Maier, K. Herfen, R. Hospes, Clinical examinations on gilts with puerperal septicaemia and toxaemia, Tier. Praxis Ausg. Gros. Nut., 26, 332-338 (1998)

6. J.C. Branstad, R.F. Ross, Lactation Failure in Swine, Iowa St. Univ. Vet., 49(1), Article 8 (1987)

7. N. Devillers, J. Le Dividich, A. Prunier, Influence of colostrum intake on piglet survival and immunity, Animal, 5, 1605-1612 (2011)

8. G.P. Martineau, Postpartum dysgalactia syndrome and mastitis in sows, In: E. Aiello, ed. The Merck Veterinary Manual, pp. 1020-1024 (Merck Co. Inc., Whitehouse Station, N. J., USA, 1998)

9. G. Reiner, B. Hertrampf, H.R. Richard, Dysgalactia in the sow postpartum - a review with special emphasis on pathogenesis, Tierärztliche Praxis Ausgabe Grosstiere Nutztiere, 37, 305-318 (2009)

10. R. Preißler, Genomweite Assoziationsstudie zur Untersuchung der genetischen Variation des postpartalen Dysgalaktie-Syndroms bei Sauen, Inaugural-dissertation, $126 \mathrm{p}$ (2013)

11. I. Gerjets, N. Kemper, Coliform mastitis in sows: a review, J. Swine Health Prod., 17, 97-105 (2009)

12. G.P. Martineau, C. Farmer, O. Peltoniemi, Mammary System, In: Diseases of Swine, 4th Edition (Publishing House John Wiley\&Sons, West Sussex, UK, 2012) pp. 270-293
13. T. Stiehler, Rectal and vaginal body temperature in early postpartum sows and its relation to serum concentration of acute phase proteins, Dissertation (Zugl, Berlin, Freie Universität Berlin, 2015)

14. P.J.J. De Winter, M. Verdonck, L.A. de Kruif, Endometritis and vaginal discharge in the sow. Devriese and F. Haesebrouck, Anim. Reprod. Sci., 28, 51-58.

15. G.P. Martineau, Y. Le Treut, D. Guillou, A. WaretSzkuta, Postpartum dysgalactia syndrome: A simple change in homeorhesis? J. Swine Health Prod., 21(2), 85-93 (2013)

16. A.D. Gooneratne, P.E. Hartmann, H.M. Nottage, The initiation of lactation in sows and the mastitismetritis-agalactia syndrome, Anim. Reprod. Sciences, 5, 135-140 (1982)

17. B. Anjelowski, Stagnation and the significance of the syndrome on post-spawned disgalacciya kajpharmskiodgleduvanitematoritsi in the republic of Makedonia, Doctoral dissertation. 126 p. (2017)

18. S.J. Furniss, Measurement of rectal temperature to predict 'mastitis, metritis and alagactia' (MMA) in sows after farrowing, Prev. Vet. Med., 5, 133-139 (1987)

19. S. Hoy, Investigations on influence of different housing factors on frequency of puerperal diseases in sows, Prakt. Tierarzt, 83, 990-996 (2002)

20. Guidelines for the diagnosis, therapy and prevention of diseases of the reproductive organs and mammary gland in pigs, approved by the Veterinary Department of the Ministry of Agriculture of the Russian Federation on February 5, 2001. No. 13-403 / 0007 (Moscow) 16 p. 